\title{
Non-Institutional Independent Tumor Boards Beneficial Impact on Post-Graduate Medical Training
}

\author{
Ahmed Nadeem Abbasi ${ }^{*}$, , Sohail Rasool ${ }^{2}$, Muhammad Tahir Bashir ${ }^{3}$ \\ ${ }^{1}$ Department of Oncology, The Aga Khan University Hospital, Karachi, Pakistan. \\ ${ }_{2}^{2}$ International Coordinator, Faisalabad City Tumor Board, General Practitioner, Portlaoise, Republic of Ireland. \\ ${ }^{3}$ Department of Medical Oncology, Faisalabad Medical University, Faisalabad, Pakistan.
}

Keywords: Tumor board, Multidisciplinary approach, Education, Postgraduate training, Team building, Quality healthcare.

The doctors who are going through our postgraduate residency training programs are tomorrow's specialists who will be playing pivotal roles as healthcare policy decision-makers. To establish site-specific multidisciplinary tumor boards, we have to rely on our present-day resident's leadership skills.

We intend to provide meaningful specific patient-centered goals to our postgraduate students who are our future specialist healthcare providers. We are witnessing a slow positive change towards shared care and the implementation of multidisciplinary culture. This is high time to develop modules with a specific learning objective of providing high-quality leadership skills to all our postgraduate trainees. Effective and efficient team-building skills will enable them to initiate and maintain multidisciplinary professional processes complying with international standards [1].

College of Physicians and Surgeons Pakistan (CPSP) offers 73 fellowships and 22 membership postgraduate structured training programs. CPSP is recognized globally as a postgraduate degree awarding institution. The CPSP was established in Karachi Pakistan in 1962. By virtue of untiring progressive efforts of CPSP successive councils and the postgraduate fellows have enabled this esteemed College in gaining international recognition for its qualifications comprising of fellowship and membership programs. The CPSP with these progressive achievements today assumes a distinguished and prestigious position among the institutions of postgraduate medical education in the world [2].

Tempus Fugit, residency training years pass by very quickly, therefore, unless and until we incorporate well-structured leadership skills development sessions in our postgraduate programs. Ideally, these sessions have to be conducted by specialist trainers from the very first year of residency training. This skill development process is a continuous endeavor that will be continued progress during all the years of training and during the end of year training briefings, we can gauge the managerial capacity of each trainee. Hopefully, with the help of robust professional development, we can

*Address correspondence to this author at the Department of Oncology, The Aga Khan University Hospital, Karachi, Pakistan.

Email: nadeem135@gmail.com expect to see a specialist who can stand on his or her own feet to initiate and maintain innovative processes while providing services as a professional specialist who will be a valuable team player. We are witnessing a positive change in our cancer patients' care. The establishment of multidisciplinary site-specific tumor boards is one of the milestones in the comprehensive management of a patient's treatment journey [3].

Inclusion of a certain topic in the Curricula of any Postgraduate Medical Education program is done with an intention to achieve certain pre-defined professional objectives. Their practices will be affected by the presence or absence of multidisciplinary culture provided to them during their training years. The absence of site-specific tumor board activity in their training institution will lead to their deficiencies in the delivery of open professional multidisciplinary team care. There is a definite interdependent relationship between the quality of postgraduate training and the expected leadership capacity of future specialists. If our trainee residents are well trained in the art and science of process development, they will play a pivotal role in the future improvement of all patient-centered processes, cancer management via consensus building in multi-disciplinary deliberations before the commencement of the first modality of treatment. This is only possible if we provide well-structured practical training in effective professional team building. Postgraduate trainee residents who came to Pakistan for short-term training have also shared their positive views regarding process development that is happening in Pakistan [4].

In this day and age, one cannot work in isolation and to deliver high-quality treatment to our patients we have to follow international standards. Cancer can originate from any organ of the body and the management of cancer attracts a wide range of medical disciplines. Institutional site-specific multidisciplinary tumor boards cover all cancer patients who are referred for specialist care in that particular institute. Cases are discussed and deliberated in the presence of an expert panel of site-specific specialists. Our concept of non-institutional tumor boards had emerged due to the lack of one 
hundred percent case discussions in institutional tumor boards. Furthermore, there are health care providers who are offering treatment to cancer patients in piecemeal. There are many centers which are providing one or two modality-based cancer services and they refer their cases to another institute for further care. Non-institutional tumor boards cover these cases and by virtue of these multidisciplinary boards, we can provide much better care based on recommendations made by a panel of independent experts. Our team strongly recommends the formation of such tumor boards in every city of the country as in our opinion this can be a lifeline for our cancer patients, especially those who are getting their treatment in a place where institutional tumor boards do not exist [5].

In Pakistan, we have developed non-institutional and non-territorial tumor boards, for example, the city tumor board was established at a neutral venue in Karachi and it is being conducted on Sunday mornings [6]. Our experience of City Tumor Board Karachi, which was established in 2010 lead to a campaign by the slogan of 'Tumor Board Saves Lives' in which we are advising our specialist colleagues to establish both types of multidisciplinary tumor boards, viz, institutional boards and the independent city tumor boards. Post-graduate trainees actively participate in this independent non-institutional Tumor Board regularly. The post-graduate residents present cases and take part in the deliberations on each case. The final recommendations are made by the practicing specialists, but, one of the beneficiaries of this multi-disciplinary activity is the trainees. They get the opportunity of interacting with faculty colleagues of their own specialty and also faculty and residents belonging to other specialties. This interaction is quite valuable for them and the authors of this manuscript strongly recommend active participation of post-graduate trainees in their institutional site-specific multi-disciplinary team (MDT) Tumor Boards on a regular basis. This activity needs to be incorporated as an essential activity for all post-graduate residents who are getting training in all fields related to comprehensive cancer care. We quote and follow contemporary published clinical practice guidelines, like the National Comprehensive Cancer Network (NCCN) guidelines of United States [7], National Institute of Clinical Excellence (NICE) of United Kingdom [8], etc. All these international practice guidelines emphasize the mandatory requirement of the establishment of a multidisciplinary team that will discuss the case and provides a written consensus recommendation that is conveyed to the patient.

Faisalabad City Tumor Board is another exemplary endeavor that was formally established in April 2021. Specialists from various institutions of Faisalabad gather and present their cancer patients' cases for an open forum deliberation. All concerned disciplines are represented in this multidisciplinary forum. The Faisalabad City Tumor Board has academic support from international and national advisory forums. We are quite hopeful that with time more and more cities will formulate and commence these independent non-institutional and non-territorial boards. Present-day trainee residents will be taking the roles of specialists and CPSP supervisors in the future and we are expecting a positive progressive change in our multidisciplinary team culture leading to better healthcare outcomes. The impact of site-specific multi-disciplinary institutional tumor boards has a positive impact on high-quality post-graduate training systems [9]. We wish to quote findings of an umbrella review published in January 2020 which is also showing a beneficial impact of these boards on patient's clinical management [10].

Pakistani post and undergraduate Trainees have published several peer reviewed manuscripts in national and international scientific journals. We wish to quote few pertinent published papers that were written by the trainees with their senior faculty teachers $[11,12]$. In Table $\mathbf{1}$, we have listed contemporary published literature items that are authored by trainees and their respective specialization training supervisors [13-15]. Various themes relevant to multidisciplinary tumor boards were published in these eight manuscripts which are being referenced in the reference list present at the end.

City Tumor Board is non-institutional independent Multi-Disciplinary Tumor Boards in which doctors bring cases of cancer patients for discussion. These patients are diagnosed and treated in hospitals where tumor boards are not being conducted. This non-institutional tumor board only deals with adult patients. Institutional Boards have specialized Pediatric MDT services. All adult specialties are involved in it. This is an open to all, independent multidisciplinary activity that has not restricted to selected institutions. In actual fact, mostly those cases are discussed in City Tumor Board which belong to hospitals where, there is no institutional tumor board. Information is circulated via all forms of social media, e-mails and dedicated WhatsApp groups. One audit is already published [6] that analyzed data of 264 cases. Trainee students from various post and undergraduate training programs get maximum educational benefit by attending these MDT meetings. Table $\mathbf{1}$ is showing some of the published work of this team. Students working in institutes where regular Tumor Boards are being conducted are getting involved in publishing multidisciplinary approach based manuscripts. Dedicated properly designed research studies are required to ascertain quantitative impact of these activities. 
TRAINEES PUBLISHED MANUSCRIPTS

Table 1. Themes Covered in Peer Reviewed Publications Done by Trainees.

\begin{tabular}{|c|c|c|c|c|}
\hline No. & $\begin{array}{c}\begin{array}{c}\text { No. of Trainee } \\
\text { Authors }\end{array} \\
\end{array}$ & $\begin{array}{c}\text { Authors Trainees' } \\
\text { names are underlined }\end{array}$ & Theme & Bibliography \\
\hline 1 & 1 & $\begin{array}{l}\text { Ali SME, Sahito B, } \\
\text { Chinoy MA, Abbasi AN, } \\
\text { Khatri A. }\end{array}$ & Spinal MDT & $\begin{array}{l}\text { Cord Compression from Bony Metastasis: An } \\
\text { Important Quality of Life Issue which can be } \\
\text { Resolved by a Spinal MDT Tumor Board. Nat J } \\
\text { of Health Sc. } 2020 \text { Vol; } 5 \text {, Issue 3; pages 92-93. }\end{array}$ \\
\hline 2 & 4 & $\begin{array}{l}\text { Khan AMH, Bhatti IA, } \\
\text { Nizami MA, Khan J, } \\
\text { Abbasi AN; }\end{array}$ & $\begin{array}{l}\text { MDT \& } \\
\text { Undergraduate } \\
\text { Training }\end{array}$ & $\begin{array}{l}\text { Tumor board establishment; Standpoint of our } \\
\text { future doctors; International Journal of Multidis- } \\
\text { ciplinary and Current Educational Research } \\
\text { (IJMCER) 2021;Vol: } 3 \text { Issue:3 p110-113. }\end{array}$ \\
\hline 3 & 1 & Waqas M, Abbasi AN. & $\begin{array}{l}\text { Neuro Oncology } \\
\text { MDT }\end{array}$ & $\begin{array}{l}\text { Establishment of site specific multi-disciplinary } \\
\text { tumour boards in Pakistan: Sharing experience } \\
\text { of neuro oncology team based at a tertiary care } \\
\text { university hospital. Jnl of Pak Medical Assoc. } \\
\text { March 2017. Letter to editor.Vol:67, No:3 page } \\
486 .\end{array}$ \\
\hline 4 & 2 & $\begin{array}{l}\text { Abbasi AN, Abrar S, } \\
\text { Qureshi BM. }\end{array}$ & $\begin{array}{l}\text { MDT Tumor Boards. } \\
\text { Patients Quality Care }\end{array}$ & $\begin{array}{l}\text { Site-Specific Multi Disciplinary Tumour Board } \\
\text { is an important milestone in cancer patient's } \\
\text { treatment journey; J Pak Med Assoc; Vol. } 70 \text {, } \\
\text { No. 10, October } 2020 .\end{array}$ \\
\hline 5 & 2 & $\begin{array}{l}\text { Abbasi AN, Abrar S, } \\
\text { Khan BM. }\end{array}$ & $\begin{array}{l}\text { MDT Tumor Board } \\
\text { Quality }\end{array}$ & $\begin{array}{l}\text { How can we prove that tumor board is a } \\
\text { mandatory component of high-quality cancer } \\
\text { care? Nat J of Health Sc, } 2020,5,58-59 \text {. }\end{array}$ \\
\hline 6 & 2 & $\begin{array}{l}\text { Abbasi AN, Jibril H, } \\
\text { Qureshi BM. }\end{array}$ & $\begin{array}{l}\text { MDT Students } \\
\text { Survey }\end{array}$ & $\begin{array}{l}\text { Awareness of site-specific tumour boards } \\
\text { among Final Year Pakistani medical students. } \\
\text { Pak J of Radiol; Jan } 2018 \text { 28(1). page 35- } 39 .\end{array}$ \\
\hline 7 & 2 & $\begin{array}{l}\text { Abbasi AN, Qureshi BM, } \\
\text { Karim MU. }\end{array}$ & $\begin{array}{l}\text { MDT Decision } \\
\text { Making }\end{array}$ & $\begin{array}{l}\text { "Impact of Multidisciplinary Team (MDT) } \\
\text { Meetings and Decision-Making on Cancer } \\
\text { Management in LMIC" in its current form for } \\
\text { publication in CHEST. accepted for publication } \\
\text { on } 13 \text { Aug 2020. Manuscript ID } \\
\text { CHEST-20-4172. }\end{array}$ \\
\hline 8 & 3 & $\begin{array}{l}\text { Abbasi AN, Karim MU, } \\
\text { Ali N, Hafiz A, Qureshi } \\
\text { BM. }\end{array}$ & $\begin{array}{l}\text { MDT Tumor Boards } \\
\text { as Lifeline of cancer } \\
\text { patients }\end{array}$ & $\begin{array}{l}\text { Multidisciplinary Team Tumour Boards are a } \\
\text { Lifeline for Our Cancer Patients in Lower \& } \\
\text { Middle Income Countries. Clinical Oncology } \\
\text { (Royal College of Radiologists).2016 Jul 24: } \\
\text { S0936-6555(16)30181-9. }\end{array}$ \\
\hline
\end{tabular}




\section{CONFLICT OF INTEREST}

Declared none.

\section{ACKNOWLEDGEMENTS}

Declared none.

\section{REFERENCES}

[1] Turner S, Lehman M. Are we training the next generation of proficient radiation oncologists, or just better examination candidates? J Med Imaging Radiat Oncol 2016; 60(3): 389-92. DOI: $10.1111 / 1754-9485.12457$

[2] https://www.cpsp.edu.pk/about-cpsp.php. [Accessed on 07/14/2021].

[3] Abbasi AN. Establishment and maintenance of quality of site-specific multidisciplinary tumor boards in Pakistan. J Coll Physicians Surg Pak 2016; 26(10): 805-7.

[4] Karim MU, Aviero AD, Khan AM, Abbasi AN. Importance of international exchange programme in postgraduate training. J Coll Physicians Surg Pak 2018; 28(12): 981-2. DOI: 10.29271/jcpsp.2018.12.981

[5] Abbasi AN, Karim MU, Ali N, Hafiz A, Qureshi BM. Multidisciplinary team tumour boards are a lifeline for our cancer patients in lower and middle income countries. Clin Oncol 2016; 28(12): 799. DOI: 10.1016/j.clon.2016.07.003

[6] Asghar AH, Abbasi AN, Rizvi S. City tumour board Karachi: An innovative step in multidisciplinary consensus meeting and its two years audit. JPMA 2013; 63(12): 1534-5.

[7] https://www.nccn.org/. [Accessed on 09/29/2021].

[8] https://www.nice.org.uk/guidance/published?type=cg [Accessed on 09/29/2021].

[9] Pillay B, Wootten AC, Crowe H, et al. The impact of multidis- ciplinary team meetings on patient assessment, management and outcomes in oncology settings: A systematic review of the literature. Cancer Treat Rev 2016; 42: 56-72. DOI: 10.1016/j.ctrv.2015.11.007

[10] Specchia ML, Frisicale EM, Carini E, et al. The impact of tumor board on cancer care: Evidence from an umbrella review. BMC Health Services Res 2020; 20(1): 1-4. DOI: 10.1186/s12913-020-4930-3

[11] Khan BM, Mansha MA, Ali N, Abbasi AN, Ahmed SM, Qureshi BM. Hidradenocarcinoma: Five years of local and systemic control of a rare sweat gland neoplasm with nodal metastasis. Cureus 2018; 10(6): e2884.

[12] Parkes J, Hess C, Burger H, et al. Recommendations for the treatment of children with radiotherapy in low-and middle-income countries (LMIC): A position paper from the Pediatric Radiation Oncology Society (PROS-LMIC) and Pediatric Oncology in Developing Countries (PODC) working groups of the International Society of Pediatric Oncology (SIOP). Pediatr Blood Cancer 2017; 64 (Suppl 5). PMID: 29297617. DOI: $10.1002 / p b c .26903$

[13] Ali SM, Sahito B, Chinoy MA, Abbasi AN, Khatri A. Cord compression from bony metastasis: An important quality of life issue which can be resolved by a spinal MDT tumor board. Nat J Health Sci 2020; 5(3): 92-3. DOI: 10.21089/njhs. 53.0092

[14] Khan AMH, Bhatti IA, Nizami MA, Khan J, Abbasi AN. Tumor board establishment; Standpoint of our future doctors. IJMCER 2021; 3(Issue 3): 110-3.

[15] Waqas M, Abbasi AN. Establishment of site specific multi-disciplinary tumour boards in Pakistan: Sharing experience of neuro oncology team based at a tertiary care university hospital. J Pak Med Assoc 2017; 67(3): 486. 